\title{
Distinct Roles for Nigral GABA and Glutamate Receptors in the Regulation of Dendritic Dopamine Release under Normal Conditions and in Response to Systemic Haloperidol
}

\author{
William S. Cobb and Elizabeth D. Abercrombie \\ Center for Molecular and Behavioral Neuroscience, Rutgers University, Newark, New Jersey 07102
}

The regulation of dendritic dopamine release in the substantia nigra (SN) likely involves multiple mechanisms. GABA and glutamate inputs to nigrostriatal dopamine neurons exert powerful influences on dopamine neuron physiology; therefore, it is probable that GABA and glutamate likewise influence dendritic dopamine release, at least under some conditions. The present studies used in vivo microdialysis to determine the potential roles of nigral GABA and glutamate receptors in the regulation of dendritic dopamine release under normal conditions and when dopamine signaling in the basal ganglia is compromised after systemic haloperidol administration. Nigral application of the $\mathrm{GABA}_{\mathrm{A}}$ receptor antagonist bicuculline by reverse dialysis significantly increased spontaneous dopamine efflux in the SN. However, spontaneous dopamine efflux in the SN was not significantly affected by local application of the glutamate receptor antagonists 6-cyano-7-nitroquinoxaline-2,3-dione or (士)-3-[2-carboxypiperazine-4-yl]-propyl-1-phosphonic acid. Systemic haloperidol administration significantly increased the extracellular dopamine measured in the SN. Blockade of nigral $\mathrm{GABA}_{\mathrm{A}}$ receptors by local bicuculline application did not alter this effect of systemic haloperidol, despite the bicucullineinduced increase in spontaneous dendritic dopamine efflux. In contrast, nigral application of either glutamate receptor antagonist significantly attenuated the increases in dendritic dopamine efflux elicited by systemic haloperidol. These data suggest that under normal conditions, activity of GABA afferents to SN dopamine neurons is an important determinant of the spontaneous level of dendritic dopamine release. Circuit-level changes in the basal ganglia involving an increased glutamatergic drive to the $\mathrm{SN}$ appear to underlie the increase in dendritic dopamine release that occurs in response to systemic haloperidol administration.

Key words: basal ganglia; dendritic dopamine release; microdialysis; Parkinson's disease; substantia nigra; subthalamic nucleus
Nigrostriatal dopamine neurons release dopamine similarly from axon terminals and somatodendritic regions (Geffen et al., 1976; Paden et al., 1976; Wilson et al., 1977; Heeringa and Abercrombie, 1995). Dendritic dopamine release is probably regulated by dopamine neuron electrical activity (Rice et al., 1997; Jaffe et al., 1998), which importantly depends on the influence of GABA- and glutamate-containing afferents (Scarnati and Pacitti, 1982; Johnson et al., 1992; Smith and Grace, 1992; Chergui et al., 1994; Tepper et al., 1995; Iribe et al., 1999; Paladini et al., 1999). Therefore, the activity state of GABA and glutamate afferent inputs influences somatodendritic dopamine release; moreover, such regulation may differ depending on the relative state of basal ganglia functioning.

Dopamine neurons are densely innervated by inhibitory GABAergic afferents (Nitsch and Riesenberg, 1988; Bolam and Smith, 1990; Tepper et al., 1995) and also receive excitatory glutamatergic inputs (Jackson and Crossman, 1983; Kita and Kitai, 1987; Naito and Kita, 1994). Nigral application of GABAergic antagonists increases the extracellular dopamine recovered in the striatum and substantia nigra (SN) (Westerink et

Received Sept. 7, 2001; revised Nov. 14, 2001; accepted Nov. 25, 2001.

This research was supported by United States Public Health Service Grant NS19608. We thank Dr. David W. Miller and James A. Zackheim for assistance with the data analysis and the manuscript, Dr. James M. Tepper for helpful discussions, and Alma Pangilinan and Mary Antonuccio for technical assistance.

Correspondence should be addressed to William S. Cobb, 197 University Avenue, Newark, NJ 07102-1814. E-mail: cobb@axon.rutgers.edu.

Copyright (C) 2002 Society for Neuroscience $0270-6474 / 02 / 221407-07 \$ 15.00 / 0$ al., 1992b), suggesting that endogenous GABAergic tone in the $\mathrm{SN}$ maintains a powerful inhibitory influence over spontaneous dopamine release from nerve terminals and dendrites. Stimulation of nigral glutamatergic afferents to the SN or nigral application of glutamate agonists increases striatal and nigral dopamine efflux (Mintz et al., 1986; Araneda and Bustos, 1989; Westerink et al., 1992a,b; Rosales et al., 1994). Thus, glutamatergic input to dopamine neurons can stimulate dendritic dopamine release and, like GABA, glutamate can regulate nerve terminal and dendritic dopamine release. Whether a tonic glutamate influence participates in the regulation of spontaneous dendritic dopamine release, however, has yet to be determined.

Examining the relative contributions of GABA and glutamate afferents to the $\mathrm{SN}$ in relation to evoked changes in dendritic dopamine release may add additional insight into the relative involvement of these inputs in the regulation of this process under normal versus pathological conditions. Dopamine loss within the basal ganglia in Parkinson's disease is thought to result in an increased role for afferent control of the SN by glutamate as well as a diminution of the concomitant influence of nigral GABAergic inputs (Miller and DeLong, 1987; Bergman et al., 1990; Robledo and Feger, 1991; Bergman et al., 1994; Kreiss et al., 1996). Systemic haloperidol administration produces an acute drug-induced parkinsonian state and increases somatodendritic dopamine efflux (Abercrombie et al., 1998; Bradley et al., 2000). Furthermore, catalepsy produced by haloperidol administration is disrupted by glutamate receptor antagonist application into the subthalamic nucleus (STN). The latter provides glutamatergic 
input to the $\mathrm{SN}$ and is known to be hyperactive in parkinsonism (see above) (Miller and DeLong, 1987; Miwa et al., 1998b). Interestingly, intracerebroventricular application of the glutamate antagonist kynurenate abolishes increases in dopamine neuron firing rate produced by systemic haloperidol (Tung et al., 1991).

The aim of this study was to investigate potential differences in the relative roles of nigral GABA and glutamate afferents in the regulation of spontaneous dendritic dopamine release compared with evoked dendritic dopamine release produced by systemic haloperidol administration.

\section{MATERIALS AND METHODS}

Animals. Adult male Sprague Dawley rats (Zivic-Miller Laboratories, Pittsburgh, PA) were used in all experiments. Animals were housed individually in plastic shoebox cages and supplied with food and water $a d$ libitum. Animals were kept under conditions of constant temperature $\left(21^{\circ} \mathrm{C}\right)$ and humidity $(40 \%)$ and maintained on a $12 \mathrm{hr}$ light/dark cycle. Rats weighed between 275 and $325 \mathrm{~g}$ at the time of each experiment. All efforts were made to minimize animal suffering and to limit the number of animals used for these experiments. Animal procedures were conducted in accordance with the National Institutes of Health Guide for the Care and Use of Laboratory Animals (revised 1985), and all protocols were approved by the Rutgers University Institutional Animal Care and Use Committee.

Microdialysis probe construction and implantation. Microdialysis probes were of the vertical concentric design adapted from previously described methods (Abercrombie and Finlay, 1991). Polyethylene tubing (PE-10 tubing; Clay Adams, Parsippany, NJ) served as the inlet to the probe, and fused silica capillary tubing (Polymicro Technologies, Phoenix, AZ) served as the outlet. The silica tubing was inserted through the wall and into the lumen of the PE-10 tubing such that it extended $10 \mathrm{~mm}$ past the tubing tip. A semipermeable microdialysis membrane (molecular weight cutoff $=6000$; outer diameter $=200 \mu \mathrm{m}$; Spectrum Laboratories, Rancho Dominguez, CA) was placed over the end of the exposed silica tubing, and the tip of the membrane was plugged with epoxy. The silica tubing was fixed into position with epoxy, and the exposed portion of the dialysis membrane was coated with a thin epoxy layer, leaving a $1.5 \mathrm{~mm}$ long active exchange area at the end of the probe. The microdialysis probes were continuously perfused with artificial CSF solution (in mM: $147 \mathrm{NaCl}, 2.5 \mathrm{KCl}, 1.3 \mathrm{CaCl}_{2}, 0.9 \mathrm{MgCl}_{2}, \mathrm{pH} \approx 7.4$ ) at a rate of 1.5 $\mu \mathrm{l} / \mathrm{min}$ with a syringe pump (Harvard Apparatus, Holliston, MA).

Before implantation, probes were calibrated to determine relative in vitro recovery rates to exclude dysf unctional microdialysis probes. Probes were considered dysfunctional if recovery was not within the range of $10-15 \%$ relative recovery. Animals were anesthetized with chloral hydrate $(400 \mathrm{mg} / \mathrm{kg}$, i.p. $)$ or sodium pentobarbital $(50 \mathrm{mg} / \mathrm{kg}$, i.p.) and mounted into a stereotaxic device (David Kopf Instruments, Tujunga, $\mathrm{CA})$. Probes were set at a $30^{\circ}$ lateral angle and implanted into the SN at the following coordinates: anteroposterior, $-5.1 \mathrm{~mm}$; mediolateral, \pm 5.6 $\mathrm{mm}$ relative to bregma; and dorsoventral, $-8.0 \mathrm{~mm}$ below dura (Paxinos and Watson, 1986; Heeringa and Abercrombie, 1995). The probe assembly was fixed to the skull with fast-curing dental cement and three skull screws. The inlet of the probe was connected to a single-channel fluid swivel (Instech Laboratories, Inc., Plymouth Meeting, PA), thus allowing the animal to move freely. Experiments were conducted at least $18 \mathrm{hr}$ after probe implantation.

Analysis of dialysate. Dialysis samples $(20 \mu \mathrm{l})$ were collected every 15 min and analyzed for dopamine content by HPLC coupled with electrochemical detection. A Velosep RP-18 column $(100 \times 3.2 \mathrm{~mm}$; Applied Biosystems, Inc., Foster City, CA) was used, and the mobile phase was composed of $0.1 \mathrm{~m}$ sodium acetate buffer, $\mathrm{pH}$ 4.1, $0.1 \mathrm{~mm}$ EDTA, $1.2 \mathrm{~mm}$ sodium octyl sulfate, and $6.5 \%(\mathrm{v} / \mathrm{v})$ methanol. An electrochemical detector (Waters model 460; Millipore Corp., Bedford, MA) with an amperometric electrode set at an applied potential of $+0.6 \mathrm{~V}$ was used. A solvent delivery pump (model LC-10AD; Shimadzu Corp., Columbia, MD) delivered the mobile phase at a flow rate of $0.7 \mathrm{ml} / \mathrm{min}$. The system was calibrated daily with $20 \mu \mathrm{l}$ of $10 \mathrm{nM}$ standard solution in $0.1 \mathrm{M}$ perchloric acid. Retention time was used to identify dopamine, which was quantified on the basis of peak height. The limit of detection for dopamine in this analysis was $\sim 0.3 \mathrm{pg}$.

Experimental manipulations. Haloperidol was dissolved in $\sim 40 \mu \mathrm{l}$ of glacial acetic acid, diluted $(0.5 \mathrm{mg} / \mathrm{ml})$ in $0.9 \%$ saline solution $(\mathrm{v} / \mathrm{v})$, and administered via intraperitoneal injection at a dose of $0.5 \mathrm{mg} / \mathrm{kg}$. In all experiments, at least three consecutive microdialysis samples were collected before drug administration to establish baseline values for spontaneous dopamine efflux (variability of $<10 \%$ ). In experiments involving local application of bicuculline methchloride, 6-cyano-7nitroquinoxaline-2,3-dione (CNQX), or ( \pm )-3-[2-carboxypiperazine4-yl]-propyl-1-phosphonic acid (CPP) by reverse dialysis, the drug was diluted in the artificial CSF perfusate solution (CNQX and bicuculline, $100 \mu \mathrm{M}$; CPP, $50 \mu \mathrm{M}$.) The applied concentrations of CNQX and CPP were chosen on the basis of previous studies demonstrating effective antagonism of evoked increases in striatal dopamine efflux produced by kainate and NMDA, respectively (Keefe et al., 1992). In all interaction experiments, antagonists were continuously applied locally via the probe beginning $90 \mathrm{~min}$ before systemic haloperidol administration to allow sufficient time to achieve a new stable baseline.

Data analysis. Data are expressed as mean \pm SEM. Values represent picograms of dopamine per $20 \mu \mathrm{l}$ microdialysis sample. Dialysate values are not corrected for in vitro probe recovery. To examine the effect of drug treatments on extracellular dopamine recovery, postdrug samples were compared with the average baseline, and within-group effects were analyzed using a one-way ANOVA with repeated measures over time coupled to Dunn's post hoc test $(p<0.05)$. Between-group differences were assessed by a two-way ANOVA with repeated measures over time $(p<0.05)$.

Histology. After completion of each experiment, the animal was given a lethal dose of sodium pentobarbital and perfused transcardially with buffered formalin $(10 \%)$; the brain was then removed. Coronal slices of $50 \mu \mathrm{m}$ thickness were stained with cresyl violet to verify placement of microdialysis probes within the SN (Fig. 1). Only data from experiments with probe placement within the region of the $\mathrm{SN}$ ventral to the pars compacta were included in the data analyses.

Materials. Chloral hydrate, sodium pentobarbital, haloperidol, CNQX, $\mathrm{CPP}$, and bicuculline methchloride were purchased from Sigma (St. Louis, MO). All other reagents and chemicals were of the highest purity commercially available (Fischer Scientific, Springfield, NJ).

\section{RESULTS}

\section{Effect of local application of GABA or glutamate receptor antagonists on extracellular dopamine in the SN}

Local perfusion with the $\mathrm{GABA}_{\mathrm{A}}$ receptor antagonist bicuculline $(100 \mu \mathrm{M})$ significantly increased dopamine release in the SN from a baseline level of $0.9 \pm 0.1 \mathrm{pg} / \mathrm{sample}$ to an overall absolute peak level of $2.6 \pm 0.2 \mathrm{pg} / \mathrm{sample}\left(F_{(10,60)}=30.5 ; p<0.01 ; n=7\right)$ (Fig. $2)$. This manipulation produced increased behavioral activation and contralateral turning in most animals lasting for the duration of bicuculline application in the SN. Local perfusion with the non-NMDA glutamate receptor antagonist CNQX $(100 \mu \mathrm{M}) \mathrm{did}$ not significantly alter the extracellular dopamine level in the SN $\left(F_{(6,30)}=0.83 ; p=0.56 ; n=6\right)$ (Fig. 2). Reverse dialysis with the NMDA glutamate receptor antagonist CPP $(50 \mu \mathrm{M})$ also did not significantly alter spontaneous dopamine efflux in the $\mathrm{SN}\left(F_{(6,42)}=\right.$ 1.38; $p=0.24 ; n=8$ ) (Fig. 2). No noticeable behavioral effect was observed with the application of either glutamate receptor antagonist.

\section{Effect of local application of GABA or glutamate receptor antagonists on increases in extracellular dopamine in the SN produced by intraperitoneal haloperidol}

Systemic administration of the mixed $\mathrm{D}_{2} / \mathrm{D}_{1}$ dopamine receptor antagonist haloperidol $(0.5 \mathrm{mg} / \mathrm{kg})$ significantly increased extracellular dopamine in the $\mathrm{SN}$ from $1.1 \pm 0.1 \mathrm{pg} / \mathrm{sample}$ to an overall absolute peak level of $1.7 \pm 0.2 \mathrm{pg} / \mathrm{sample}\left(F_{(10,60)}=4.16\right.$; $p<0.01 ; n=7$ ) (Fig. 3). This effect was observed in the first postdrug sample and was at least $2.5 \mathrm{hr}$ in duration. Animals displayed markedly decreased levels of behavioral activation for the duration of the experiment.

In separate groups of animals, GABA or glutamate receptor 
A
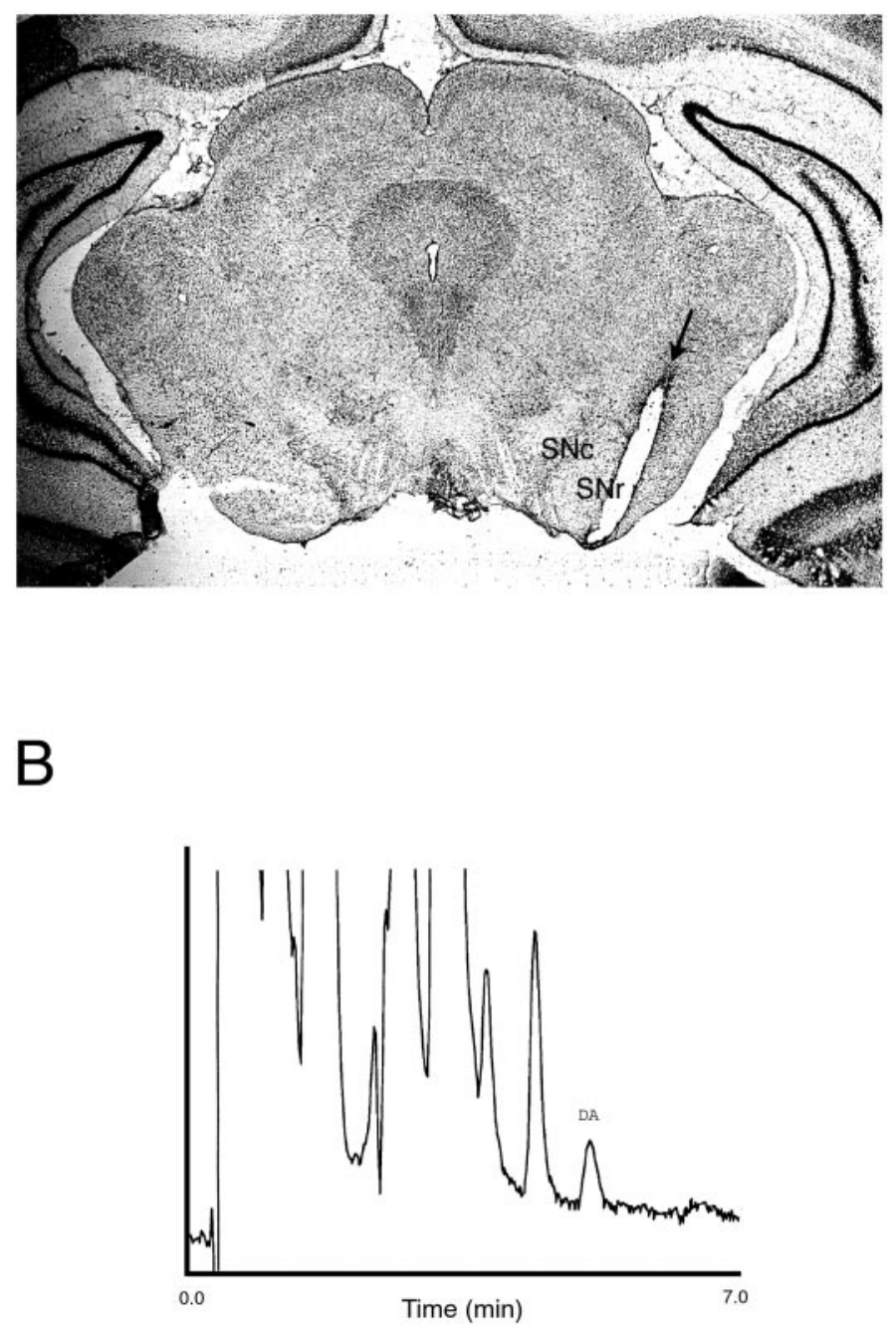

Figure 1. A, Cresyl violet-stained coronal section at the level of the midbrain showing microdialysis probe localization within the SN. The arrow denotes the probe track. $S N c$, Substantia nigra pars compacta; $S N r$, substantia nigra pars reticulata. $B$, Chromatogram obtained from a $20 \mu 1$ dialysate sample under baseline conditions. The dopamine $(D A)$ peak observed in this chromatogram is equal to $1.0 \mathrm{pg}$.

antagonists were applied into the $\mathrm{SN}$ via the microdialysis probe, and the effect on haloperidol-induced increases in dendritic dopamine efflux was investigated. Intranigral application of bicuculline $(100 \mu \mathrm{M})$ caused an increase in extracellular dopamine in the $\mathrm{SN}$ that reached a plateau $90 \mathrm{~min}$ after application and was sustained at this new level (Fig. 4A). Based on this observation, intraperitoneal administration of haloperidol was performed 90 min after onset of local drug application in the present experiments.

As observed previously, nigral application of bicuculline (100 $\mu \mathrm{M}$ ) elicited an increase in spontaneous dopamine efflux in the SN from a baseline level of $0.9 \pm 0.1 \mathrm{pg} / \mathrm{sample}$ to $2.4 \pm 0.2 \mathrm{pg} /$ sample at $90 \min \left(F_{(6,42)}=39.13 ; p<0.01 ; n=8\right)$ (Fig. $4 A$ ). Ninety minutes after bicuculline was applied via the probe in the $\mathrm{SN}$, systemic haloperidol $(0.5 \mathrm{mg} / \mathrm{kg}$, i.p. $)$ elicited an additional significant increase in dendritic dopamine release from $2.4 \pm 0.2$ $\mathrm{pg} / \mathrm{sample}$ to an overall absolute peak level of $2.8 \pm 0.3 \mathrm{pg} / \mathrm{sample}$
CNQX $(100 \mu \mathrm{M})$

CPP $(50 \mu \mathrm{M})$

$\mathrm{BIC}(100 \mu \mathrm{M})$

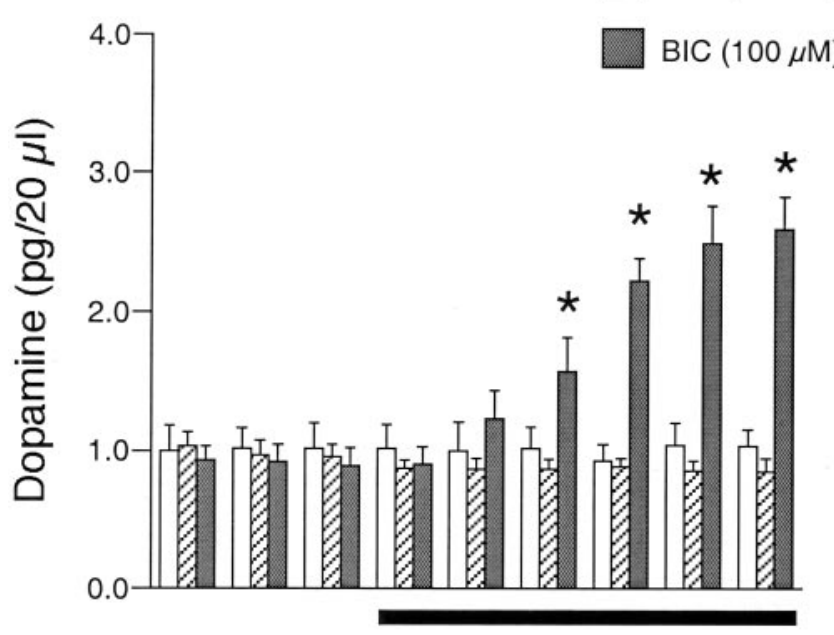

15 min samples

Figure 2. Extracellular dopamine levels after reverse dialysis application of bicuculline, CNQX, and CPP. Bicuculline significantly increased spontaneous dopamine efflux in the SN $(n=7)$. Local application of CNQX $(n=6)$ or CPP $(n=8)$ had no effect on basal levels of extracellular dopamine in the SN. The horizontal bar denotes local drug application by reverse dialysis. All data are mean $\pm \mathrm{SEM} ;{ }^{*} p<0.05$.

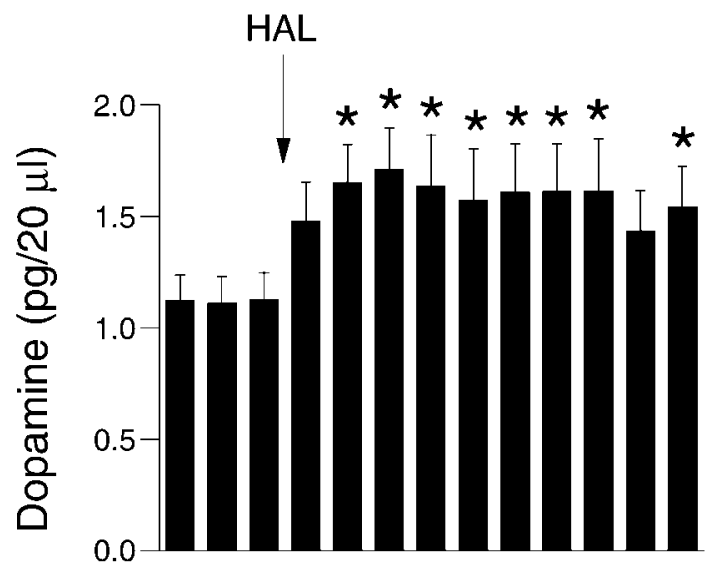

15 min samples

Figure 3. Extracellular dopamine after systemic administration of haloperidol $(H A L)$. Systemic administration of haloperidol $(0.5 \mathrm{mg} / \mathrm{kg}$, i.p.; arrow) produced a significant increase in extracellular dopamine within the SN $(n=7)$. All data are mean \pm SEM; ${ }^{*} p<0.05$.

$\left(F_{(6,42)}=3.69 ; p<0.01 ; n=8\right)$ (Fig. $\left.4 A\right)$. A significant interaction was obtained $\left(F_{(5,65)}=3.66 ; p<0.01\right)$ between the increase in extracellular dopamine in the $\mathrm{SN}$ produced by haloperidol in the presence of bicuculline and the dopamine levels observed with bicuculline alone $(n=7)$. A direct comparison of the absolute increase in nigral dopamine (picograms per sample) elicited by systemic haloperidol alone or by systemic haloperidol administration during local application of bicuculline revealed no significant difference between the two conditions $\left(F_{(4,52)}=4.03\right.$; $p=0.40$ ) (Fig. 4B).

Nigral application of CNQX did not affect spontaneous den- 


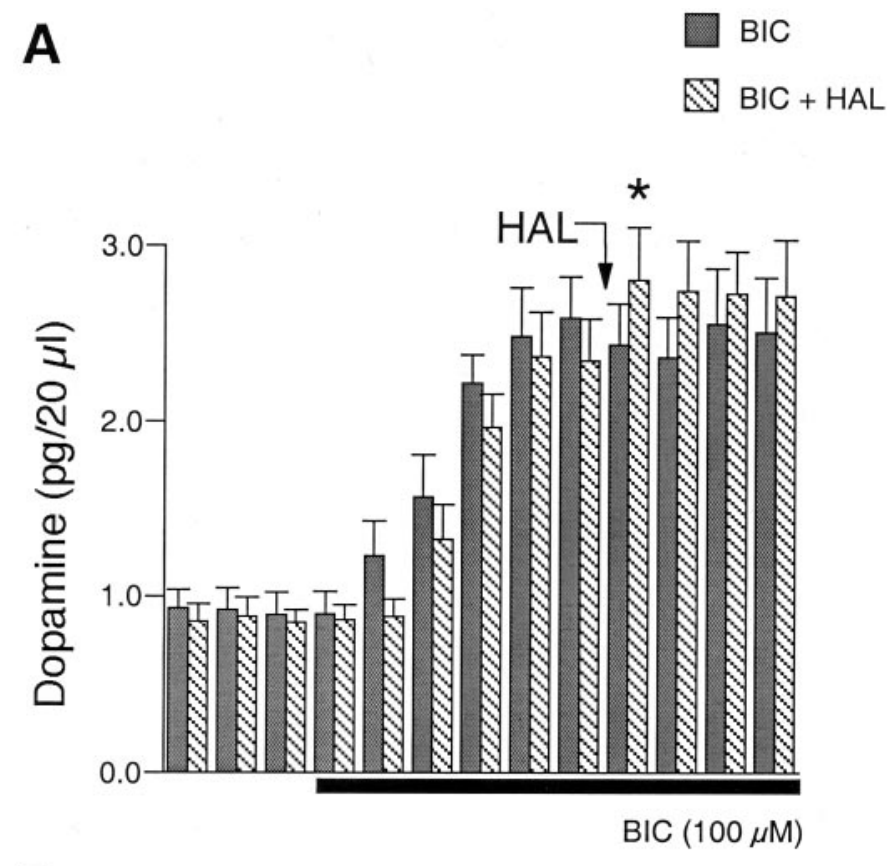

B

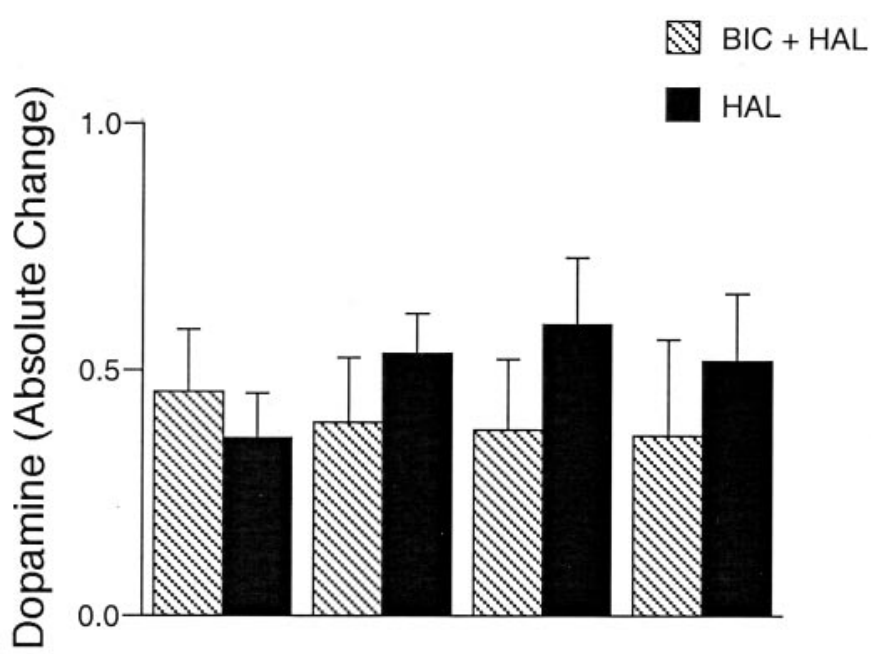

15 min samples

Figure 4. $A$, Systemic administration of haloperidol (HAL) significantly increased extracellular dopamine in the $\mathrm{SN}$ in the presence of local bicuculline $(B I C)$. After the maximum effect of reverse application of bicuculline (horizontal bar) was reached, subsequent systemic administration of haloperidol $(0.5 \mathrm{mg} / \mathrm{kg}$; arrow) significantly increased extracellular dopamine in the SN compared with the sample immediately preceding systemic administration of haloperidol $(n=8)$. Moreover, a significant interaction existed between the increase in nigral dopamine recovery produced by systemic administration of haloperidol in the presence of local bicuculline and that produced by bicuculline alone $(n=7)$. $B$, The absolute dopamine increase measured after systemic administration of haloperidol in the presence of intranigral bicuculline compared with haloperidol alone under control conditions (Fig. 3). Values were calculated by subtracting postdrug values from the average of the two baselines immediately before systemic administration of haloperidol in the presence or absence of intranigral bicuculline. All data are mean \pm SEM; ${ }^{*} p<0.05$.

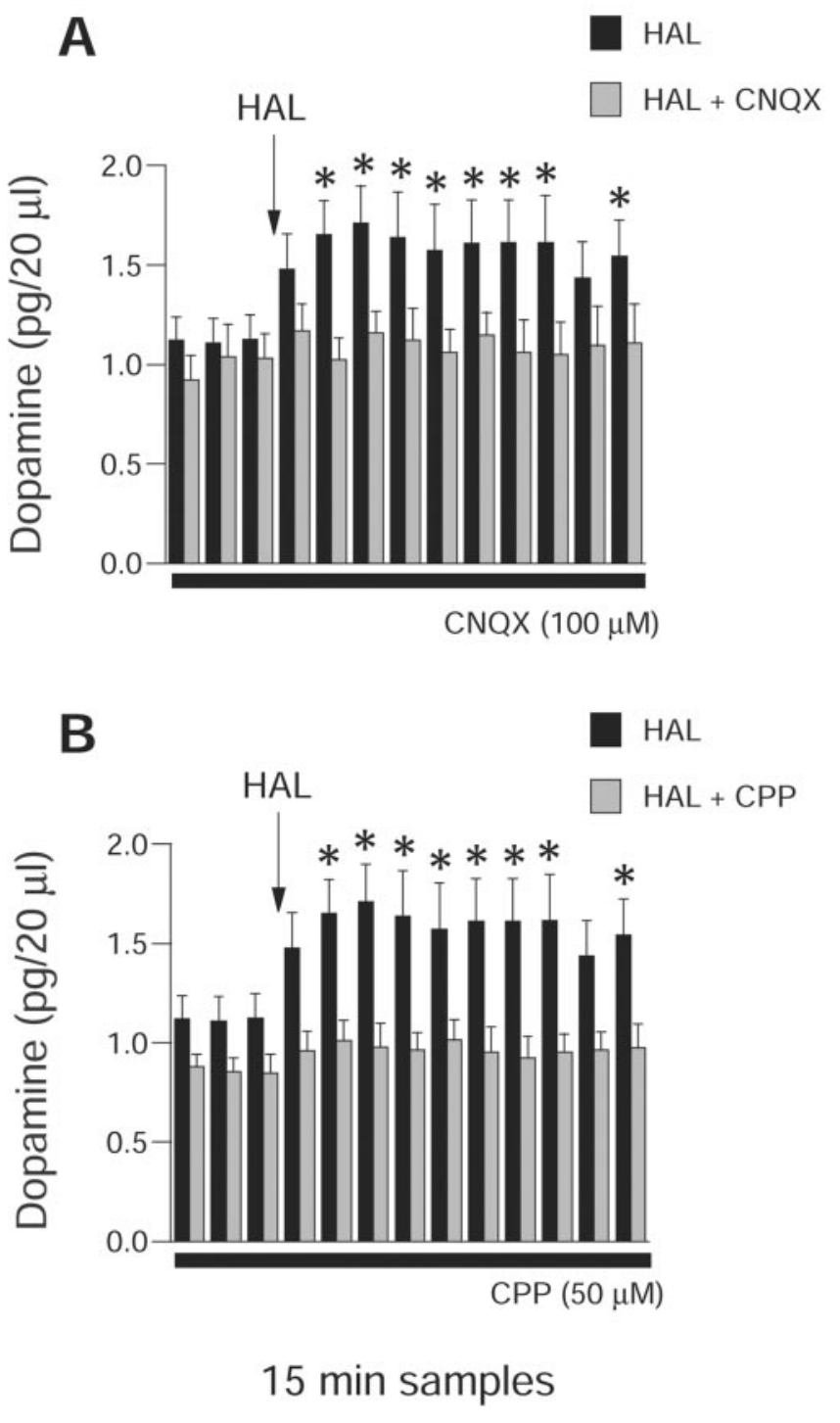

Figure 5. $A$, Reverse dialysis with CNQX attenuated the ability of systemic haloperidol $(H A L)(0.5 \mathrm{mg} / \mathrm{kg}$; arrow) to significantly increase extracellular dopamine in the $\mathrm{SN}(n=6)$. There was a significant difference between the effect of haloperidol in the presence of CNQX and haloperidol alone. $B$, Reverse dialysis with CPP blocked the ability of systemic haloperidol $(0.5 \mathrm{mg} / \mathrm{kg}$; arrow $)$ to increase extracellular dopamine in the SN $(n=8)$. There was a significant difference between the effect of haloperidol in the presence of CPP and haloperidol alone. The horizontal black bar denotes local drug application by reverse dialysis. All data are mean $\pm \mathrm{SEM} ;{ }^{*} p<0.05$.

dritic dopamine release, consistent with previous results (see above). However, local CNQX completely blocked the increased dopamine efflux in the $\mathrm{SN}$ produced by systemic haloperidol $\left(F_{(10,50)}=0.56 ; p=0.84 ; n=6\right)$ (Fig. $\left.5 A\right)$. Therefore, a significant interaction was obtained when the effects of systemic haloperidol on extracellular dopamine in the SN in the presence and absence of intranigral CNQX were compared $\left(F_{(12,132)}=2.75 ; p<0.01\right)$. The ability of systemic haloperidol to increase dendritic dopamine release also was blocked by the presence of CPP in the dialysis perfusate $\left(F_{(10,70)}=0.75 ; p=0.68 ; n=8\right)$ (Fig. $\left.5 B\right)$. Likewise, a significant interaction was obtained when the effects of systemic haloperidol on extracellular dopamine in the $\mathrm{SN}$ in the presence and absence of intranigral CPP were compared $\left(F_{(12,156)}=4.65 ; p<0.01\right)$. 


\section{DISCUSSION}

The goal of the present studies was to offer insight into the regulation of dendritic dopamine release in the SN by GABA and glutamate, thus contributing to the present understanding of the functioning of basal ganglia circuitry under normal conditions and under conditions when dopamine neurotransmission is compromised. We first examined the involvement of nigral GABA and glutamate receptors in the regulation of spontaneous dopamine release in the $\mathrm{SN}$. In subsequent experiments, we examined the involvement of nigral GABA and glutamate signaling in the increase in dendritic dopamine efflux that was observed to occur in response to intraperitoneal administration of haloperidol.

We observed that nigral application of the $\mathrm{GABA}_{\mathrm{A}}$ receptor antagonist bicuculline via the microdialysis probe significantly increased the extracellular dopamine measured in the SN of unanesthetized rats. Under the same conditions, local application of either the AMPA/kainate glutamate receptor antagonist CNQX or the NMDA glutamate receptor antagonist CPP failed to significantly alter spontaneous dopamine efflux in the SN. The increase in dendritic dopamine release elicited by nigral bicuculline application suggests that nigral GABA afferents maintain a strong inhibitory influence on dendritic dopamine release under normal conditions. In contrast, our data suggest that nigral glutamate afferents play a relatively minor role in the regulation of dendritic dopamine efflux in this situation. As a result, the level of spontaneous dendritic dopamine release normally is determined by activity in GABA afferents rather than by glutamatergic neurotransmission.

We found that dendritic dopamine efflux was increased to a similar extent by systemic haloperidol regardless of whether $\mathrm{GABA}_{\mathrm{A}}$ receptors were blocked by nigral application of bicuculline. The finding that the increase in the spontaneous efflux of dopamine in the SN produced by local application of bicuculline is additive with the increase in this variable produced in response to systemic haloperidol administration indicates that separate mechanisms are involved in these two effects. Disinhibition of dendritic dopamine release caused by a net reduction in the activity of GABA inputs to SN dopamine neurons cannot account for the effect of systemic haloperidol on dendritic dopamine release in the $\mathrm{SN}$, because dopamine continues to increase after systemic administration of haloperidol in the presence of local bicuculline. An alternative mechanism such as increased glutamate drive to the $\mathrm{SN}$ and/or an emergent autoreceptor effect is likely to explain the haloperidol-induced increases in dendritic dopamine release observed under these conditions. We observed that nigral application of the glutamate receptor antagonist CNQX or CPP did effectively prevent haloperidol-induced increases in dendritic dopamine efflux. Thus, we infer from these results that increased glutamatergic drive to the $\mathrm{SN}$ mediates increases in dendritic dopamine efflux in response to systemic administration of haloperidol under these conditions. Moreover, this action of glutamate apparently can be effected via both non-NMDA and NMDA receptor signaling pathways.

The STN is a potential source for increased glutamate drive to the $\mathrm{SN}$ in response to systemic haloperidol. Previous work has shown that activation of the STN elicits an increase in nigral dopamine efflux that is mediated by glutamate (Mintz et al., 1986; Rosales et al., 1994, 1997). Evidence consistent with an activation of the STN in response to systemic haloperidol comes from studies showing that systemic haloperidol increases the induction of c-Fos in STN targets, including the SN (Miwa et al., 1998a).
Furthermore, intraperitoneal injection of group II metabotropic glutamate receptor antagonists reverses haloperidol-induced catalepsy (Bradley et al., 2000), and postural asymmetries are produced by systemic haloperidol when STN activity is altered unilaterally (Miwa et al., 1998b). Although these studies cite the STN as a potential source for the hyperactive glutamatergic drive to dopamine neurons after systemic administration of haloperidol, it is noted that electrophysiological studies fail to show a consistent net effect of haloperidol on the firing rate of individual STN neurons (Hollerman et al., 1992). Other glutamatergic afferents to the SN, including the cortex and pedunculopontine nucleus, also potentially could contribute to the stimulation of dendritic dopamine release in response to systemic administration of haloperidol, but the mechanism whereby systemic haloperidol might activate these structures is less clear based on current models of basal ganglia function (Scarnati et al., 1986; Canteras et al., 1990; Di Loreto et al., 1992; Naito and Kita, 1994; Futami et al., 1995).

Haloperidol elicits a profound parkinsonian state in humans, and acute administration of haloperidol elicits at least some of the same behavioral and physiological effects that are produced by nigrostriatal dopamine lesion in animals (Ungerstedt and Arbuthnott, 1970; Ranje and Ungerstedt, 1977; Ross, 1990; Zimbroff et al., 1997). Therefore, to the extent that systemic haloperidol administration can be viewed as acutely modeling the changes that occur in the basal ganglia circuitry in Parkinson's disease (see the introductory remarks), the present data further underscore the likelihood that functional changes in the afferent regulation of SN dopamine neuron function, by glutamate in particular, may contribute to the disease phenotype in the early stages of the disorder. It has been suggested that an increased influence of glutamatergic input from the STN to the $\mathrm{SN}$ is present during the presymptomatic period of Parkinson's disease and that this change in afferent regulation of surviving dopamine neurons contributes to the maintenance of dopaminergic function in the nigrostriatal system during this period (Bezard et al., 1997, 1999). The present data support this notion as well as underscore the contribution of dendritic dopamine release in the SN as an essential component of basal ganglia function (Robertson and Robertson, 1988, 1989; Timmerman and Abercrombie, 1996; Abercrombie and DeBoer, 1997; Crocker, 1997).

The proposed circuit-based mechanism for the stimulatory action of systemic haloperidol on dendritic dopamine release in the $\mathrm{SN}$ is consistent with the hypothesis that relief from autoreceptor-mediated inhibition plays a minor role in this effect (Starke et al., 1989). In vitro electrochemical studies have shown that electrically stimulated nigral dopamine release is at best weakly influenced by autoinhibition (Cragg and Greenfield, 1997; Hoffman and Gerhardt, 1999). Furthermore, significant increases in nigral dopamine efflux are elicited by systemic but not nigral administration of $\mathrm{D}_{2}$ dopamine receptor antagonists (Westerink and de Vries, 1989; Westerink et al., 1994; Abercrombie et al., 1998). Therefore, an alteration in the activity of basal ganglia circuitry and resulting changes in afferent glutamate input to the $\mathrm{SN}$, rather than antagonism of local impulse- and releaseregulating $\mathrm{D}_{2}$ autoreceptors on nigrostriatal dopamine neurons, best explains the increase in dendritic dopamine release observed in response to systemic haloperidol. An apparently limited role of nigral autoreceptors in the regulation of dendritic dopamine release contrasts strongly with the incontrovertible role of autoregulation in the control of nerve terminal dopamine release. Blockade of $\mathrm{D}_{2}$ autoreceptors in the $\mathrm{SN}$ by haloperidol increases dopamine neuron firing rates (Groves et al., 1975; Pucak and 
Grace, 1994), and systemic, nigral, or striatal administration of $\mathrm{D}_{2}$ antagonists increases dopamine efflux in the striatum (Zetterstrom et al., 1984; Westerink and de Vries, 1989; Westerink et al., 1992b). Thus, it appears that local blockade of nigral autoreceptors can increase the activity of nigrostriatal dopamine neurons and stimulate nerve terminal dopamine release without affecting dendritic dopamine release. This situation adds further credence to the intriguing possibility that dopamine neuron firing rate and dendritic dopamine release may not always be parallel. Compartmentalization of ionic conductances on membrane regions of the dopamine neuron might allow for dendritic excitability to be independent of firing rate, so that under certain conditions nerve terminal and dendritic dopamine release can be uncoupled (Nedergaard et al., 1988; Grace, 1990; Trent and Tepper, 1991; Tepper et al., 1997).

In summary, nigral dopamine release in the intact basal ganglia appears to be subject to strong regulation by GABA afferents with little or no apparent influence of glutamate neurotransmission. However, when dopamine neurotransmission in this circuitry is impaired by systemic haloperidol administration, excitatory effects of glutamate on dendritic dopamine efflux supersede the tonic inhibition by GABA, and increases in nigral dopamine release occur. Therefore, these results reveal distinct roles for GABA and glutamate afferents to the $\mathrm{SN}$ in the regulation of dendritic dopamine release in these two conditions. Additional investigation into the exact anatomic substrates that underlie these findings will further elucidate the afferent regulation of somatodendritic dopamine release under normal and pathological conditions.

\section{REFERENCES}

Abercrombie ED, De Boer P (1997) Substantia nigra D1 receptors and stimulation of striatal cholinergic interneurons by dopamine: a proposed circuit mechanism. J Neurosci 17:8498-8505.

Abercrombie ED, Finlay JM (1991) Monitoring extracellular norepinephrine in brain using in vivo microdialysis and HPLC-EC. In: Microdialysis in the neurosciences (Robinson TE, Justice JB, eds), pp 253-274. New York: Elsevier.

Abercrombie ED, DeBoer P, Heeringa MJ (1998) Biochemistry of somatodendritic dopamine release in substantia nigra: an in vivo comparison with striatal dopamine release. Adv Pharmacol 42:133-136.

Araneda R, Bustos G (1989) Modulation of dendritic release of dopamine by $N$-methyl-D-aspartate receptors in rat substantia nigra. J Neurochem 52:962-970.

Bergman H, Wichmann T, DeLong MR (1990) Reversal of experimental parkinsonism by lesions of the subthalamic nucleus. Science 249:1436-1438.

Bergman H, Wichmann T, Karmon B, DeLong MR (1994) The primate subthalamic nucleus. II. Neuronal activity in the MPTP model of parkinsonism. J Neurophysiol 72:507-520.

Bezard E, Boraud T, Bioulac B, Gross CE (1997) Compensatory effects of glutamatergic inputs to the substantia nigra pars compacta in experimental parkinsonism. Neuroscience 81:399-404.

Bezard E, Boraud T, Bioulac B, Gross CE (1999) Involvement of the subthalamic nucleus in glutamatergic compensatory mechanisms. Eur J Neurosci 11:2167-2170.

Bolam JP, Smith Y (1990) The GABA and substance P input to dopaminergic neurones in the substantia nigra of the rat. Brain Res 529:57-78.

Bradley SR, Marino MJ, Wittmann M, Rouse ST, Awad H, Levey AI, Conn PJ (2000) Activation of group II metabotropic glutamate receptors inhibits synaptic excitation of the substantia nigra pars reticulata. J Neurosci 20:3085-3094.

Canteras NS, Shammah-Lagnado SJ, Silva BA, Ricardo JA (1990) Afferent connections of the subthalamic nucleus: a combined retrograde and anterograde horseradish peroxidase study in the rat. Brain Res 513:43-59.

Chergui K, Akaoka H, Charlety PJ, Saunier CF, Buda M, Chouvet G (1994) Subthalamic nucleus modulates burst firing of nigral dopamine neurones via NMDA receptors. NeuroReport 5:1185-1188.

Cragg SJ, Greenfield SA (1997) Differential autoreceptor control of somatodendritic and axon terminal dopamine release in substantia nigra, ventral tegmental area, and striatum. J Neurosci 17:5738-5746.
Crocker AD (1997) The regulation of motor control: an evaluation of the role of dopamine receptors in the substantia nigra. Rev Neurosci 8:55-76.

Di Loreto S, Florio T, Scarnati E (1992) Evidence that non-NMDA receptors are involved in the excitatory pathway from the pedunculopontine region to nigrostriatal dopaminergic neurons. Exp Brain Res 89:79-86.

Futami T, Takakusaki K, Kitai ST (1995) Glutamatergic and cholinergic inputs from the pedunculopontine tegmental nucleus to dopamine neurons in the substantia nigra pars compacta. Neurosci Res 21:331-342.

Geffen LB, Jessell TM, Cuello AC, Iversen LL (1976) Release of dopamine from dendrites in rat substantia nigra. Nature 260:258-260.

Grace AA (1990) Evidence for the functional compartmentalization of spike generating regions of rat midbrain dopamine neurons recorded in vitro. Brain Res 524:31-41.

Groves PM, Wilson CJ, Young SJ, Rebec GV (1975) Self-inhibition by dopaminergic neurons. Science 190:522-528.

Heeringa MJ, Abercrombie ED (1995) Biochemistry of somatodendritic dopamine release in substantia nigra: an in vivo comparison with striatal dopamine release. J Neurochem 65:192-200.

Hoffman AF, Gerhardt GA (1999) Differences in pharmacological properties of dopamine release between the substantia nigra and striatum: an in vivo electrochemical study. J Pharmacol Exp Ther 289:455-463.

Hollerman JR, Abercrombie ED, Grace AA (1992) Electrophysiological, biochemical, and behavioral studies of acute haloperidol-induced depolarization block of nigral dopamine neurons. Neuroscience 47:589-601.

Iribe Y, Moore K, Pang KC, Tepper JM (1999) Subthalamic stimulationinduced synaptic responses in substantia nigra pars compacta dopaminergic neurons in vitro. J Neurophysiol 82:925-933.

Jackson A, Crossman AR (1983) Nucleus tegmenti pedunculopontinus: efferent connections with special reference to the basal ganglia, studied in the rat by anterograde and retrograde transport of horseradish peroxidase. Neuroscience 10:725-765.

Jaffe EH, Marty A, Schulte A, Chow RH (1998) Extrasynaptic vesicular transmitter release from the somata of substantia nigra neurons in rat midbrain slices. J Neurosci 18:3548-3553.

Johnson SW, Seutin V, North RA (1992) Burst firing in dopamine neurons induced by $N$-methyl-D-aspartate: role of electrogenic sodium pump. Science 258:665-667.

Keefe KA, Zigmond MJ, Abercrombie ED (1992) Extracellular dopamine in striatum: influence of nerve impulse activity in medial forebrain bundle and local glutamatergic input. Neuroscience 47:325-332.

Kita H, Kitai ST (1987) Efferent projections of the subthalamic nucleus in the rat: light and electron microscopic analysis with the PHA-L method. J Comp Neurol 260:435-452.

Kreiss DS, Anderson LA, Walters JR (1996) Apomorphine and dopamine $\mathrm{D}(1)$ receptor agonists increase the firing rates of subthalamic nucleus neurons. Neuroscience 72:863-876.

Miller WC, DeLong MR (1987) Altered tonic activity of neurons in the globus pallidus and subthalamic nucleus in the primate MPTP model of parkinsonism. In: The basal ganglia, II (Carpenter MB, Jayaraman A, eds), pp 415-427. New York: Plenum.

Mintz I, Hammond C, Guibert B, Leviel V (1986) Stimulation of the subthalamic nucleus enhances the release of dopamine in the rat substantia nigra. Brain Res 376:406-408.

Miwa H, Nishi K, Fuwa T, Mizuno Y (1998a) Globus pallidus lesions inhibit the induction of c-Fos by haloperidol in the basal ganglia output nuclei in rats. Neurosci Lett 250:29-32.

Miwa H, Nishi K, Fuwa T, Mizuno Y (1998b) Postural effects of unilateral blockade of glutamatergic neurotransmission in the subthalamic nucleus on haloperidol-induced akinesia in rats. Neurosci Lett 252:167-170.

Naito A, Kita H (1994) The cortico-nigral projection in the rat: an anterograde tracing study with biotinylated dextran amine. Brain Res 637:317-322.

Nedergaard S, Hopkins C, Greenfield SA (1988) Do nigro-striatal neurones possess a discrete dendritic modulatory mechanism? Electrophysiological evidence from the actions of amphetamine in brain slices. Exp Brain Res 69:444-448.

Nitsch C, Riesenberg R (1988) Immunocytochemical demonstration of GABAergic synaptic connections in rat substantia nigra after different lesions of the striatonigral projection. Brain Res 461:127-142.

Paden C, Wilson CJ, Groves PM (1976) Amphetamine-induced release of dopamine from the substantia nigra in vitro. Life Sci 19:1499-1506.

Paladini CA, Celada P, Tepper JM (1999) Striatal, pallidal, and pars reticulata evoked inhibition of nigrostriatal dopaminergic neurons is mediated by GABA(A) receptors in vivo. Neuroscience 89:799-812.

Paxinos G, Watson C (1986) The rat brain in stereotaxic coordinates. New York: Academic.

Pucak ML, Grace AA (1994) Evidence that systemically administered dopamine antagonists activate dopamine neuron firing primarily by blockade of somatodendritic autoreceptors. J Pharmacol Exp Ther 271:1181-1192. 
Ranje C, Ungerstedt U (1977) High correlations between number of dopamine cells, dopamine levels and motor performance. Brain Res 134:83-93.

Rice ME, Cragg SJ, Greenfield SA (1997) Characteristics of electrically evoked somatodendritic dopamine release in substantia nigra and ventral tegmental area in vitro. J Neurophysiol 77:853-862.

Robertson GS, Robertson HA (1988) Evidence that the substantia nigra is a site of action for L-DOPA. Neurosci Lett 89:204-208.

Robertson GS, Robertson HA (1989) Evidence that L-dopa-induced rotational behavior is dependent on both striatal and nigral mechanisms. J Neurosci 9:3326-3331.

Robledo P, Feger J (1991) Acute monoaminergic depletion in the rat potentiates the excitatory effect of the subthalamic nucleus in the substantia nigra pars reticulata but not in the pallidal complex. J Neural Transm Gen Sect 86:115-126.

Rosales MG, Flores G, Hernandez S, Martinez-Fong D, Aceves J (1994) Activation of subthalamic neurons produces NMDA receptor-mediated dendritic dopamine release in substantia nigra pars reticulata: a microdialysis study in the rat. Brain Res 645:335-337.

Rosales MG, Martinez-Fong D, Morales R, Nunez A, Flores G, GongoraAlfaro JL, Floran B, Aceves J (1997) Reciprocal interaction between glutamate and dopamine in the pars reticulata of the rat substantia nigra: a microdialysis study. Neuroscience 80:803-810.

Ross RT (1990) Drug-induced parkinsonism and other movement disorders. Can J Neurol Sci 17:155-162.

Scarnati E, Pacitti C (1982) Neuronal responses to iontophoretically applied dopamine, glutamate, and GABA of identified dopaminergic cells in the rat substantia nigra after kainic acid-induced destruction of the striatum. Exp Brain Res 46:377-382.

Scarnati E, Proia A, Campana E, Pacitti C (1986) A microiontophoretic study on the nature of the putative synaptic neurotransmitter involved in the pedunculopontine-substantia nigra pars compacta excitatory pathway of the rat. Exp Brain Res 62:470-478.

Smith ID, Grace AA (1992) Role of the subthalamic nucleus in the regulation of nigral dopamine neuron activity. Synapse 12:287-303.

Starke K, Gothert M, Kilbinger H (1989) Modulation of neurotransmitter release by presynaptic autoreceptors. Physiol Rev 69:864-989.

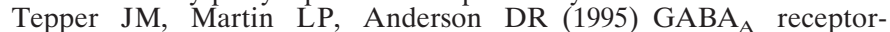
mediated inhibition of rat substantia nigra dopaminergic neurons by pars reticulata projection neurons. J Neurosci 15:3092-3103.
Tepper JM, Sun BC, Martin LP, Creese I (1997) Functional roles of dopamine D2 and D3 autoreceptors on nigrostriatal neurons analyzed by antisense knockdown in vivo. J Neurosci 17:2519-2530.

Timmerman W, Abercrombie ED (1996) Amphetamine-induced release of dendritic dopamine in substantia nigra pars reticulata: D1-mediated behavioral and electrophysiological effects. Synapse 23:280-291.

Trent F, Tepper JM (1991) Dorsal raphe stimulation modifies striatalevoked antidromic invasion of nigral dopaminergic neurons in vivo. Exp Brain Res 84:620-630.

Tung CS, Grenhoff J, Svensson TH (1991) Kynurenate blocks the acute effects of haloperidol on midbrain dopamine neurons recorded in vivo. J Neural Transm Gen Sect 84:53-64.

Ungerstedt U, Arbuthnott GW (1970) Quantitative recording of rotational behavior in rats after 6-hydroxy-dopamine lesions of the nigrostriatal dopamine system. Brain Res 24:485-493.

Westerink BH, de Vries JB (1989) On the mechanism of neuroleptic induced increase in striatal dopamine release: brain dialysis provides direct evidence for mediation by autoreceptors localized on nerve terminals. Neurosci Lett 99:197-202.

Westerink BH, Santiago M, De Vries JB (1992a) The release of dopamine from nerve terminals and dendrites of nigrostriatal neurons induced by excitatory amino acids in the conscious rat. Naunyn Schmiedebergs Arch Pharmacol 345:523-529.

Westerink BH, Santiago M, De Vries JB (1992b) In vivo evidence for a concordant response of terminal and dendritic dopamine release during intranigral infusion of drugs. Naunyn Schmiedebergs Arch Pharmacol 346:637-643.

Westerink BHC, De Boer P, Santiago M, De Vries JB (1994) Do nerve terminals and cell bodies of nigrostriatal dopaminergic neurons of the rat contain similar receptors? Neurosci Lett 167:109-112.

Wilson CJ, Groves PM, Fifkova E (1977) Monoaminergic synapses, including dendro-dendritic synapses in the rat substantia nigra. Exp Brain Res 30:161-174.

Zetterstrom T, Sharp T, Ungerstedt U (1984) Effect of neuroleptic drugs on striatal dopamine release and metabolism in the awake rat studied by intracerebral dialysis. Eur J Pharmacol 106:27-37.

Zimbroff DL, Kane JM, Tamminga CA, Daniel DG, Mack RJ, Wozniak PJ, Sebree TB, Wallin BA, Kashkin KB (1997) Controlled, doseresponse study of sertindole and haloperidol in the treatment of schizophrenia. Sertindole Study Group. Am J Psychiatry 154:782-791. 